\title{
Literature Review: Project Time-Cost Trade-Off in Construction Projects
}

\author{
Neha Tiwari, Manoj Sharma
}

\begin{abstract}
In Construction planning the major problem is reducing the time-cost and it developed the time-cost trade-off (TCTO) problem today's. The time and cost is always correlated with each other and if we assume time as valuable as money (time value of money) TVOM then the dealing with these type of problem is must be easy. In today's competitive business environment, delivering projects within the least possible time, with maximum quality and minimum cost possesses a critical issue for project managers. Project time crashing plays a crucial role in project management determining which activities duration to crash to finish the project within the stipulated time. TCTO problem in project management have been traditionally solved by two distinctive approaches like CTM, PERT, Heuristic methods and so on. In these type of paper they always try to used The Linear Programming Method. The comparative analysis between mathematically (Linear Programming method/traditional) and CTM is done by Using an example.
\end{abstract}

Index Terms - Project management; Time-cost trade-off; Discounted cash flows; Net present value; Optimization; Nonlinear programming..

\section{INTRODUCTION}

\section{Definitions of Time-cost trade-off}

One important extension to the essential network analysis technique relates to project cost/ project time tradeoff. In this extension to the essential method we assume that, for every activity, the completion time are often reduce (within limits) by spending extra money on the activity.

Normal time: - it's time taken by the project with none delay in any activity of the project. Normal time of the project doesn't contain crashing of any activities. Crash cost: - Crash cost is that the cost associated when the project is completed with crash time of the project.

Crush time: - A procedure for determining the optimal project time is to work out the traditional completion time for every critical path activity and a crash time. The crash time is that the shortest time during which an activity are often completed. The direct costs then are calculated for the traditional and crash times of every activity. Reducing project duration are often done by adjusting overlaps between activities or by reducing activities' duration. What is the rationale for a rise in direct

Neha Tiwari, Civil Engineering, RGPV/ IPS College of Technology \& Management, Gwalior, India, Phone/ Mobile 9340231804.

Manoj Sharma, Civil Engineering, RGPV/ IPS College of Technology \& Management, Gwalior, India, 9993482009 cost because the activity duration is reduced? A simple case arises within the use of overtime work. By scheduling weekend or evening work, the completion time for an activity as measured in calendar days are going to be reduced. However, extra wages must be purchased such overtime work, therefore the cost will increase. Also, overtime work is more susceptible to accidents and quality problems that has got to be corrected, so costs may increase. The activity duration are often reduced by one among the subsequent actions:

Definition and measure of quality and impact of acceleration:

Garvin (1984) proposes several dimensions of quality from which we select conformance (match with specifications) as opposed to perceived quality which is the most subjective dimension. Conformance makes quality a measure variable whereas perceived quality is a useful concept in the early design stages of a new product. As an example, smell intensity of car interior is a component of perceived quality. A thorough analysis of perceived quality may be found in Stylidis et al. (2015). For non innovative projects that are under the scope of this survey, quality as conformance to customer specifications and to technical requirements is the relevant definition. Customer specifications involve requirements related to aesthetics (fits and finishes) or to the utilisation of high quality components and raw materials to ensure a longer product life.

For applying a network model in civil engineering practice, it must be suitable for handling two features in consideration of scheduling.

(a) The first one is the possibility of changing process durations depending on their start times. This is the key to apply calendar.

(b) The second one is using maximal constraints for activities and connections. This is useful and important in practice. In linear programming method, it is possible to give only minimal constraints. For applying maximal constraint, it must be converted by multiply the assumption with $(-1)$. It effects negative process time and turning back arc which generates loops.

In case of this constraint, there is no limit to apply the solution for the models either activity on edge (AOE) or activity on node $(\mathrm{AON})$. Here, notations are related to the model AOE.

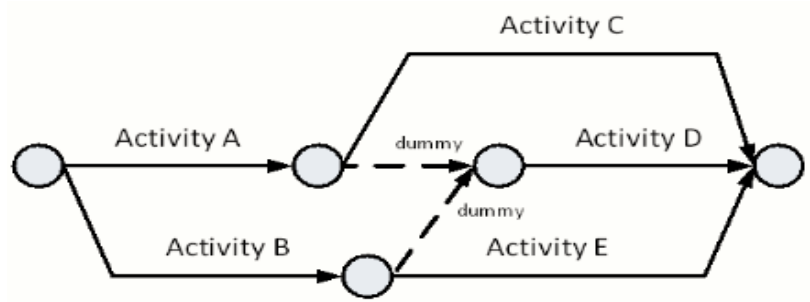


The problem is understood as time/cost trade-off problem within the project management literature. This paper reports on the second phase of a study conducted by the author on Trade-off Analysis in construction projects. In Khang and Myint (1999), model proposed by Babu and Suresh (1996) was applied to an actual cement factory construction project. Time cost quality trade-off has been thereafter researched from a mathematical point of view using heavy mathematical programming methods and softwares. This paper focuses more on the decision making aspect of the trade-off analysis and uses an easily available, user friendly Microsoft Excel Solver Add-in for analysis. This research also validates with real data most of the findings by Khang and Myint in their original work. The importance of time/cost trade-offs in projects are recognized since the event of the critical path method (CPM) within the late 1950s [1]. Sustainable project management requires the resources to be used in an economical and sustainable way [2-4].Therefore, the duration of project activities can be treated as discrete non-increasing functions of the cost. This leads to the discrete time/cost trade-off problem (DTCTP) [1]. Harvey and Patterson [5] and Hindelang and Muth [6] first proposed the DTCTP, which is a special case of the multi-mode resource-constrained project scheduling problem [7].The paper is organized as follows: In the next section we briefly define the deterministic time-cost trade-off problem, then relevant researches belong to it and performance is carried out manually with an empirical on CPM/PERT.

To start scheduling the project, an arbitrary date should be set for the start event in the project's network diagram. Usually this value is set to zero. Scheduling computation consists of two tracking through the network, forward tracking and backward tracking. The earliest possible date to start each activity is determined by forward tacking, and the latest possible date to finish the ones is obtained by backward tracking. The Earliest possible date to start an activity (ES) is the earliest date that all of its predecessor activities have been finished. The Latest possible date to Finish an activity (LF) is the latest date that none of its successor activities would be started. If an activity finishes after this date, it will have effect on the start dates of its successor activities.



PERT/CPM methods of time-cost trade-offs cares with determining what proportion to crash each of the activities so as to scale back the anticipated duration of the project to a desired value.
The major reasons which make the project managers curious about using the crashing models are:

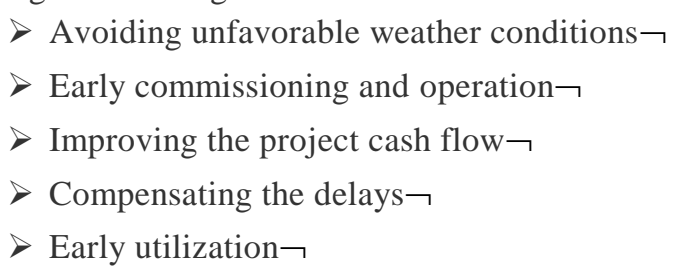

Quality issues implied by overlapping are resolved using rework to correct design flaws resulting from partial information. Thus for such projects, quality is implicitly taken into account with rework (forinstance Lin et al., 2010 for a recent contribution). Most of Time Cost Quality Trade-off Problems(TCQTP) are modelled in a similar way to Time Cost Trade-off Problems (TCTP) that have been extensively studied in the literature related to deterministic project scheduling (see Weglarz et al., 2011 for a recent survey). The time and cost parameters of a construction project have been identified as major factors of the decision making process. In critical-path method (CPM), generally, the objective is to establish a minimum project cost with reasonable time schedule based on realistic assumptions. The primary impact of project timing is money and project time is thus an equally essential factor. Since cost are often expressed as a function of your time, it's possible to work out the project time-cost trade-off (TCTO) curve which provides the minimum possible cost of completing project in its feasible time range.

\section{LITERATURE REVIEW}

H. Nikoomaram, F. Hosseinzadeh Lotfi, J. Jassbi and M. R. Shahriari (2010) The main objective in the time cost trade-off problems has always been the reduction in the total cost. In the previous researches the total cost function has been defined using some elements such as direct costs, indirect costs and opportunity costs whereas the missing element which has not been thus far discussed is value of cash (TVOM) which is considered synonymous with the cost of capital Capital cost can have an excellent impact on the optimum leads to capital- intensive projects, meaning that once we crash the starting activities during a project, the additional investment will be tied in until the top of the project; however, once we crash the ultimate activities the additional investment are going to be tied certain a way shorter period.

Veludurthi Manojkumar, Anup Wilfred S and Sridevi H (2010) Ideal tool used by construction planners are CPM\& PERT methods to analyze and reduce the project duration. As the duration is reduced the direct cost of the project increases, this results in the trade-off between the time and price wherein the indirect cost of the project will 
decrease because the duration of the project reduces. There will be a specific point at which the minimum total cost of the project are often obtained at an optimum duration. Construction managers can explore now at the design stage to scale back the time and price of the project. In this paper two techniques are wont to achieve the time-cost relationship. The two techniques used are CPM (Critical Path Method) and applied mathematics Method. The CPM is completed manually by reducing the duration of the critical path.

Hadi Mokhtari, Reza Baradaran Kazemzadeh, and Ali Salmashai (2011) The time-cost tradeoff problem (TCTP) is an important issue in the scheduling of industrial projects; it is often possible to expedite the completion of certain activities by increasing the budget. To illustrate the suggested approach, a numerical example is discussed and an overall efficiency measure is developed to line the ACS parameters so on reach more accurate results with less computational time.

S. K. Biswasa, C. L. Karmakera, T. K. Biswasa (2016) the target of the time-cost trade-off problem (TCTP) is to scale back the first project duration obtained from the critical path analysis, to satisfy a selected deadline with the minimum direct and indirect cost of the project. Direct costs include costs of fabric, labor, equipment etc. whereas indirect costs are the necessary costs of doing work which can et be related to a particular task. There are enormous research works within the arena of TCTP. In 1991, Shouman et al. constructed a framework using mixed integer applied mathematics and CPM and utilized in gas projects. The value of the study is that, by the utilization of it, minimum total cost is achieved using crashing concept. A survey on forty seven papers conducted by Agarwal et al. (2013) revealed that about $41 \%$ work was performed in construction area during the 1990-2002. Liu et al. (1995) developed a hybrid method using linear and integer programming for time-cost trade-off problem. Several researchers used dynamic programming to regulate between two important aspects of the project (Hindelang et al., 1979; Prabuddha et al., 1995; Arauzo et al., 2009).

Anagha Anirudh Galagali (2017) In today's competitive business environment, delivering projects in the least possible time, with maximum quality and minimum cost has got a critical issue for project managers. Project time crashing plays a crucial role in project management determining which activities duration to crash to finish the project within the stipulated time. It is suggested that the project quality could also be suffering from project crashing and an actual construction project has been considered to review the tradeoffs among time, cost, and quality. The purpose is to highlight the managerial insights gained, as well as pointing out key problems and difficulties faced.

Mohamed Abo - Zaid, Tamer El - Korany, Emad E. Etman, Salah El - Din F. Taher (2017) Time-cost trade-off (TCTO) is one of the viable techniques in project management. Finding near optimum solution may be a vital goal that received an excellent deal of interest. TCTO problems are traditionally solved by two distinctive approaches: heuristic methods and optimization techniques. Although heuristic methods can handle large-size projects, they are doing not guarantee optimal solutions. In this paper, an optimization model is developed employing genetic algorithm technique for TCTO problem that minimizes project direct cost and takes under consideration discounted also as net cash flow with the least possible duration.

Hongbo Li, Zhe Xu and Wenchao Wei (2018) Time/cost trade-offs in projects accelerate the execution of some activitiesby increasing the amount of non-renewable resources committed to them and therefore shorten the project duration. The discrete time/cost trade-off problem (DTCTP) has been extensively studied during the past 20 years. However, thanks to its complexity, the DTCTP-especially the DTCTP curve problem (DTCTP-C) - has only been solved for relatively small instances. To the simplest of our knowledge, there's no computational performance analysis for solving the DTCTP-C on large project instances with up to 500 activities. The objective is to get an honest appropriate efficient set for the large-scale instances. The first algorithm is predicated on the non-dominated sorting genetic algorithm II (NSGA-II) and uses a specially designed critical path-based crossover operator. The second algorithm may be a steepest descent heuristic which generates efficient solutions by iteratively solving the DTCTP with different deadlines. Computational experiments are conducted to validate the proposed algorithms on a large set of randomly generated problem instances

N.N. Klevanskiy*, S.I. Tachev, L.A. Voloshchouk (2019) the projects as aggregations. Each aggregation is decided by solving a resource availability cost problem (RACP) model to finish the project by his critical path. In the second stage, aggregations are used for its resource leveling scheduling the multi-project by a pre-specified project duration. Both stages use priority rule (PR) heuristics. Both stages are based on two parallel schedule generation schemes (SGS) and resource criteria. Each SGS uses two PR. The first SGS, a set of demands must be developed as initial solution. 


\section{METHODOLOGY AND EXAMPLES}

A typology of Time Cost Trade-off Problems can be based on the number and category of resources as well as on the type of relationship between duration and resources as shown in Figure 1. If a single renewable resource is considered such as manpower or equipment, we face Time Resource Trade-off Problems (TRTP) where the duration of an activity is assumed to be a non increasing function of the amount of the renewable resource. When this function is continuous, we get Continuous Time Resource Tradeoff Problems (CTRTP). Conversely, if this function is discrete we obtain Discrete Time Resource Trade-off Problems (DTRTP) in which any activity can be executed according to several processing modes where a mode represents a possible allocation of the resource with a corresponding duration. As can be seen in Figure 1, quality has never been integrated in Time Resource Trade-off Problems. Energy, money or raw materials are examples of single non renewable resources. But in the literature, only money is actually considered as the single non renewable resource and corresponds to the cost of any category of resources, which leads to Time Cost Trade-off Problems (TCTP). For instance money as the non renewable resource can be the cost of overtime, which is a single renewable resource, or the cost of several renewable and non renewable resources defined as the money spent for instance on components, equipments and manpower. In such Time Cost Trade-off Problems, the cost of any activity is a non increasing function of its duration. This function can either be continuous (Continuous Time Cost Trade-off Problems, CTCTP), or discrete (Discrete Time Cost Trade-off Problems, DTCTP). Three references introduce the quality in CTCTP (Babu and Suresh, 1996; Khang and Myint, 1999; Zhang et al., 2014). No less than ten references consider the quality in DTCTP where each activity can be processed in one mode amongst several execution modes, a mode corresponding to a combination of cost, duration and quality (Tran et al., 2015; Kim et al., 2012; Liberatore and Pollack-Jonhson, 2013; Tareghian and Taheri, 2006 and 2007; Mohammadipour and Sadjadi, 2016; El-Rayes and Kandil, 2005; Mungle et al., 2013; Monghasemi et al., 2015; Afshar et al., 2007). If several renewable resources are utilised and the duration of an activity is a non increasing discrete function of the amount of resources allocated to its execution, we obtain Multiple Discrete Time Cost Trade-off Problems (MDTRTP) in which the quality



Figure 1: Classification of Time Resource or Cost Trade-off Problems with quality issue has never been considered in the literature. Conversely we found four references dealing with quality in Multi mode Resource Constrained Project Scheduling Problems (MRCPSP) that include renewable and/or non renewable resources and for which the Resource Constrained Project Scheduling Problem (RCPSP) is a special case as there is a single execution mode (Icmeli-Tukel and Rom, 1997; Tiwari et al., 2009; Fu and Zhang, 2016; Afruzi et al., 2014). Several objectives, formulations and solution methods are considered in the literature, as shown in Figure 2. If the assessment of quality is binary, the objective is to minimise the rework cost or the rework duration. Otherwise, the objective is to minimise the project duration or its cost or to maximise the project quality as an aggregation of individual qualities (namely qualities of activities), the arithmetic mean being quite often used. Single objective formulations are most common and include one objective amongst the five aforementioned ones or make use of secularization approaches.

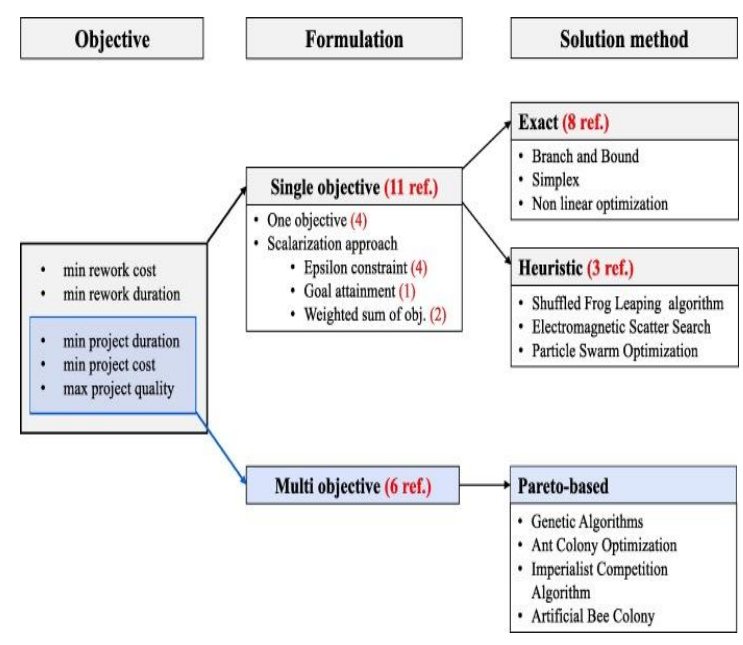

solution methods

Figure 2: Formulations and

The Methodology adopted to crash the project to answer the Problem Statement consequently solving the

Time-Cost-Quality Trade-off is depicted in the following points.

Using Microsoft Project to plan \& schedule the project: A myriad of details are considered in planning the way to coordinate all the RCC activities, in developing a sensible schedule. Of the many Project Management software, Microsoft Project is the most commonly used software to deal with all the data needed to develop schedule information. The various activities are linked by the software in terms of their predecessors and successors. Once completed, the total time required to complete the project is displayed thus answering Question 1 in the preceding section

Using Microsoft Excel to schedule the project with CPM : Each activity is scheduled by calculating its earliest \& latest times $(\mathrm{ES} / \mathrm{EF} / \mathrm{LS} / \mathrm{LF})$ in MS Excel with the help of specific formulae. The slack for an activity is the difference between its latest finish time and its earliest finish time. Thus knowing the earliest \& latest times of each activity, their corresponding slack is calculated. Those activities with 0 slack will be classified as Critical activities. 
Using Microsoft Excel Solver to crash the project and solve the Time-Cost-Quality Tradeoffs : The problem of finding the least expensive way of crashing activities and the consequent Time-Cost-Quality Trade-off can be rephrased in a form more familiar to Microsoft Excel Sheet and solved using Microsoft Excel Solver Add-in.

Updating process of CPM : During the process of implementation the plan according to the network, we may come across one or more the following possibilities:

- That some or all activities are progressing according to schedules; $\neg$

- That some or all activities are ahead of schedule; and $\neg$

- That some or all activities are behind schedule. If all activities are progressing $\neg$ consistent with the schedule, there's no need for updating the network but this is often seldom the case.

When the project is partially completed and is at an intermediate stage, it may be possible that:

1 The time duration originally assigned activities were erroneous and

2 The planner may himself feel it desirable as a result of experience.

The process of replanning and rescheduling supported the result which serve a guidance for decision made by taking into consideration the new knowledge and latest information at an intermediate stage of the project thus modifying the original network, is known as the process of updating.

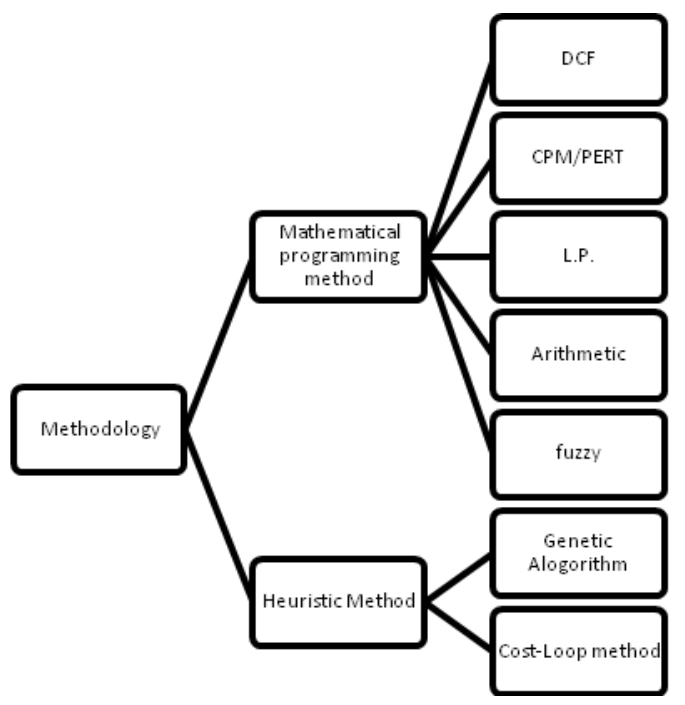

These all methodology are used in time-cost trade-off problem the example are shown the used off CPM with updating activities. So the engineer can do the work on limited money and less time.

Discounted cash flow (DCF) is a valuation method used to estimated the value of an investment based on its future cash flow DCF analysis attempts to figure out the value of company today, based on projections of how much money it will generate in the future.

PERT is a project management techniques, where by planning, scheduling, organizing, coordination and controlling uncertain activities are done. CPM is a statistical techniques of the project management in which planning, scheduling, organising, coordination and controlling of well defined activities take place.
L.P. (Linear programming) can be used in construction management to solve the optimizing use of resource, determining most economic product mix. Transportation and routing problem etc.

Construction managers plan and direction construction project on the small project they are responsible for the all the people.

Fuzzy logic has been expanded to new application areas such as construction engineering and management. Fuzzy logical methodologies are able to model subjective information, handle uncertainty, and address the lack of comprehensive data sets available for modeling in construction engineering and management.

Genetic algorithm is a model of machine learning. The algorithm can be used to find sub-optimum, if not optimum, solution to a particular problem. It explores the solution space in an intelligent manner to evolve better solutions.

Any project big or small needs its cash flow to be effectively managed so that everything runs smoothly.

Case study:

Fig. shows the networks of the project which is to be updated at the end of 12 days. The following conditions exist at the time of updating:

1. Activity 1-4 was completed as originally planned

2. Activity 1-3 was executed more rapidly than originally scheduled, and its took 8 days for its completion.

3. Activity 3-4 commenced following the completion of the activity 1-3 and was finished at the end of $11^{\text {th }}$ day.

4. Activity 4-5 was commenced following the completion of activity 3-4 and still requires 6 more days its completion.

5. Completion of activity 1-2 was delayed drastically, and it still requires 10 more days for its completion

6. Activity 2-7 will commence following the completion of activity 1-2 and will require 9 days for its completion instead for 6 days originally estimated.

7. The time required to perform activity 5-8 has been revised based on the experience on the project gained to this point its now requires 10 days in the places of 6 days originally estimated

8. No other activities have been starts and the original time estimates for these activities still appear to be accurate .

9. Update the network and determine the revised critical path.

Solution :

The updated network can now be drawn on the base of the first fig. the basis data of columns (1), (2), (4), (5) and (6) of the below table. For the activities which have already been completed.

This fig. shows original networks with $T_{E}$ and $T_{L}$ marked. 




The fig shows the original network with $\mathrm{T}_{\mathrm{E}}$ and $\mathrm{T}_{\mathrm{L}}$ marked. The critical path shown by the dark line is along activities 1 $3,3-4,4-5,4-6$, and $6-8$.

Completion time $\mathrm{t}$ is taken to be zero since they require zero time after the $12^{\text {th }}$ day. Also the earliest event time $\left(\mathrm{T}_{\mathrm{E}}\right)$ and leasted occurrence ${ }_{t}$ ime $\left(T_{L}\right)$ of each event is computed with reference to the original starting data of the project. This can be best achieved by taking $\mathrm{T}_{\mathrm{E}}$ for event 1 as equal to 12 .

After having determined the updated $\mathrm{T}_{\mathrm{E}}$ for each event corresponding $\mathrm{T}_{\mathrm{L}}$ can be computed by the backward. The update network is shown in fig. The critical path of the updated network has now changed.

It is now along activities 1-2, 2-7, 7-8 shown by dark line.

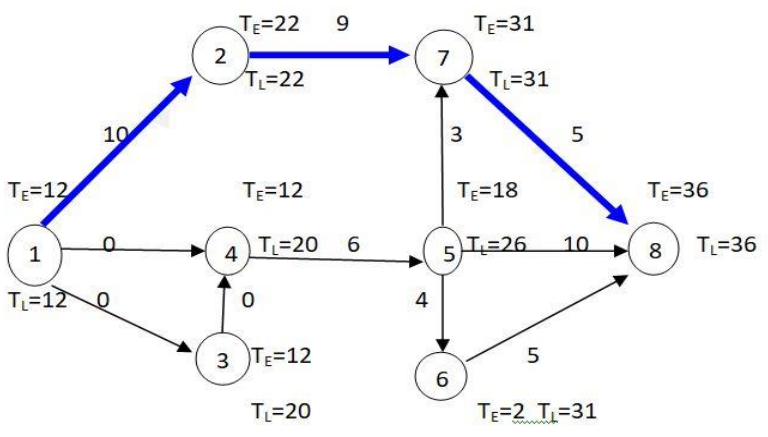

\begin{tabular}{|c|c|c|c|c|}
\hline \multirow[t]{2}{*}{ Activity } & \multicolumn{2}{|c|}{$\begin{array}{l}\text { Whether completed } \\
\text { or not }\end{array}$} & \multirow{2}{*}{$\begin{array}{l}\text { Completi } \\
\text { on time } \\
\text { required } \\
\text { for } \\
\text { activities } \\
\text { yet to } \\
\text { begin } \\
\text { (days) }\end{array}$} & \multirow{2}{*}{$\begin{array}{l}\text { Additio } \\
\text { nal } \\
\text { required } \\
\text { for } \\
\text { activitie } \\
\text { s in } \\
\text { progress } \\
\text { (days) }\end{array}$} \\
\hline & Yes/No & $\begin{array}{l}\text { If yes, time } \\
\text { taken(days } \\
\text { ) }\end{array}$ & & \\
\hline (1) & (2) & (3) & (4) & (5) \\
\hline $1-2$ & No & - & - & 10 \\
\hline $1-3$ & Yes & 8 & - & - \\
\hline $1-4$ & Yes & 5 & - & - \\
\hline $2-7$ & No & - & 9 & - \\
\hline $3-4$ & Yes & 3 & - & - \\
\hline $4-5$ & No & - & - & 6 \\
\hline $5-6$ & No & - & 4 & - \\
\hline $5-7$ & No & - & 3 & - \\
\hline $5-8$ & No & - & 10 & - \\
\hline $6-8$ & No & - & 5 & - \\
\hline $7-8$ & No & - & 5 & - \\
\hline
\end{tabular}

\section{RESULT}

As the result we can say the controlling is complementary to the planning. Once the schedule plan has been prepared and execution commenced control over the progress of work has to be exercised in order to complete the work by the stipulated date. Control involves comparing at regular intervals the particular achievement with the first plans then taking any necessary corrective action to bring things back on the schedule. Therefore, Controlling required an upward flow of information through a suitably designed reporting system. The information so fed is analysed and project plan is brought up to date with necessary variations to keep performance as per the schedule like we saw the last exam there updated fig shows how we can complete the work of the project in less days without delays the condition.

\section{CONCLUSION}

A new mathematical model for crashing PERT networks considering budget limitation was presented during this paper. The main advantages of the said model was to used the concept of time value of money (TVOM) to developed a cost of function with more applied component in comparison to other cost functions utilized in other studies. The aims of this research was time-cost trade-off analysis for a construction project. The analysis has been done for an existing project critical path method (CPM) and a heuristic method have been used to find out the cash time and crash costs the Regression analysis has been done in order to developed the relationship between the crash times and cash costs the relation between crash time and crash costs has led to developed the optimization model. Mathematical program has been used to get the minimum total costs of the project with the minimum durations. All these techniques utilized in this paper have shown a satisfactory result.

\section{REFERENCES}

1. Demeulemeester, E.L.; Herroelen,(2002) W.S. Project Scheduling: A Research Handbook; Kluwer Academic Pub:

Dordrecht, The Netherlands.

2. Dobrovolskien` e, N.; Tamoši ${ }^{-}$unien $^{`}$ e, R(2016) Sustainability-oriented financial resource allocation in a project

portfolio through multi-criteria decision-making. Sustainability, Vol.8,pp. 485 .

3. Li, H.; Dong, X.(2018) Multi-mode resource leveling in projects with mode-dependent generalized precedence

relations. Expert Syst. Appl. Vol., 97, pp. 193-204.

4. Li, H.; Xiong, L.; Liu, Y.; Li, H(2018) An effective genetic algorithm for the resource levelling problem with

generalised precedence relations. Int. J. Prod. Res. Vol, 56,pp. 2054-2075. 5. Harvey, R.T.; Patterson, J.H.(1979) An implicit enumeration algorithm for the time/cost tradeoff problem in project

network analysis. Found. Control Eng. 1979, 4, 107-117.

6. Hindelang, T.J.; Muth, J.F. . (1979) A dynamic programming algorithm for decision CPM networks. Oper. Res,

Vol, 27, 225-241.

7. Brucker, P.; Drexl, A.; Möhring, R.; Neumann, K.; Pesch, (1999), E Resource-constrained project scheduling:

Notation, classification, models, and methods. Eur. J. Oper. Res. Vol. 112 3-41.

8.Ahuja, R.K., Magnati, T.L., Orlin, J.B.,(1993),Network Flows:Theory, Algorithms and Apllications, Prentice Hall, Englewood Cliffs, NJ, pp.164 165 . 
9. Bellman, R., (1958), On a Routing Problem, Quarterly of Applied Mathematics, Vol.16(1), pp. 87 - 90.

10. Csordas, H., Malyusz, L., (2006) A Network Flow Algorithm For Time-Cost Trade-off With Technological Decision, 7th International Conference Organization, Technology and Management in Construction, Zadar, Croatia,

11. Csordas, H., , (2009) Optimal Selection of Recourses in Projects Based on the Classical Time - Cost Trade - Offs , Hungary, Periodica Polytechnica Social and Management Scienses, Vol. 17, No. 1, pp. 47 - 55.

12. Csordas, H., (2011), Activities With Multi-Parameters In Time-Cost Trade-Off, Hungary, Pollack Periodica, Vol. 6, No. 2, pp. $37-48$.

13. Dijkstra, E. W.,(1959), A Note on Two Problems in Connexion With Graphs, Numerische Mathematik, Vol.1., pp. 269 - 271.

14. Franck, B., Neumann, K., Schwindt, C. , (2001), Project scheduling with calendars OR Spektrum, Vol 23., pp. 325-334.

15. Fulkerson, R. D. January,(1961), A network flow computation for project cost curves, Management Science Vol. 2. No. 2. pp. 167 - 168.

16. Hajdu M., Malyusz L. (2009), How would you like it: cheaper or shorter?, Organization, Technology \& Management in Construction: An International Journal, Vol. 1., No. 2., pp. $59-63$.

17. Hajdu M., Klafszky E. ., (1993), An algorithm to solve the cost optimization problem through an activity on arrow type network (CPM/cost problem), Periodica Polytechnica ser. Architecture, Vol. 37., Nos 1-4, pp. 27 $-40$

18. Kelley, J. E. 1959, Critical Path Planning and Scheduling: Mathematical Basis, Operation Research, Vol. 9. No. 3.

19. Kelley, J. E. Walker, M. R. (1959), Critical Path Planning and Scheduling, Proc. the Eastern Joint Computer Conference, Boston.

20. Klafszky E., Hálózati folyamok, Budapest, (1969).

21. W. Crowston and G. L. Thompson, (1967) "Decision CPM: A method for simultaneous planning, scheduling, and control of projects," Oper. Res., vol. 15 , pp. 407-426.

22. A. Aghaie and H. Mokhtari, , (2009) "Ant colony optimization algorithm for stochastic project crashing problem in PERT networks using MC simulation," Int. J. Adv. Manuf. Technol., vol. 45, pp. 1051-1067

23. D. R. Fulkerson, (1961)"A network flow computation for project cost curves,"Manage. Sci., vol. 7, pp. 167-178, 24. P. S. Pulat and S. J. Horn, Nov. (1996) "Time-resource tradeoff problem," IEEE Trans. Eng. Manage., vol. 43, no. 4, pp. 411-417.

25. E. B. Berman, (1964) "Resource allocation in PERT network under activity continuous time-cost functions," Manage. Sci., vol. 10, pp. 734-745.

26. P. Vrat and C. Kriengkrairut, (1986) "A goal programming model for project crashing with piecewise linear time-cost trade-off," Eng. Costs Prod. Econ., vol. 10, pp. 161-172.

27. J. R. Kelley, , (1961) "Critical-path planning and scheduling: Mathematical basis," Oper. Res., vol. 9, pp. 296-320.

28. R. F. Deckro, J. E. Hebert, W. A. Verdini, P. H. Grimsurd, and E. Venkateshwar, (1995) "Nonlinear time-cost tradeoff models in project management," Comput. Ind. Eng., vol. 28, pp. 219-229.

29. S. A. Burns, L. Liu, and C. Weifeng, (1996). "The Lp/Ip hybrid method for construction time cost trade of analysis," Constr. Manage. Econ., vol. 14, pp. 265-275, 30. J. Buddhakulsomsiri and D. Kim, , (2006) "Properties of multi-mode resourceconstrained project scheduling problems with resource vacations and activity splitting," Eur. J. Oper. Res., vol. 175, pp. 279-295. 31. N. Siemens, , (1971) "A simple CPM time-cost tradeoff algorithm," Manage. Sci.,vol. 17, pp. B354-B363. 